\title{
FAULTS OF BUSES AND COACHES IN THE ASPECTS OF SECURING SAFETY IN ROAD TRAFFIC
}

\author{
Jan Filipczyk \\ Silesian University of Technology, Faculty of Transport \\ Krasinskiego Street 8, 40-019 Katowice, Poland \\ e-mail: jan.filipczyk@polsl.pl
}

\begin{abstract}
The safety of buses in road traffic is very important because of potential hazards of peoples' life and health, damage and loss of freight and high costs of crash effects. The technical state of all vehicles has been examined during required periodical inspections, but in spite of this, the technical conditions of large number of vehicles have been poor.

The range of inspections and their frequency have been determined according to the law of each country. The methodology and frequency has been determined in accordance with domestic legislation. The methodology of technical inspections concerns only some important systems of vehicles but not all. For example, anti-lock systems, retarders, adaptive cruise control systems, speed limitation devices etc. have not been examined. The results of examinations of 120 buses and coaches have been presented in this paper. Tests were carried out in scope of securing safety in road traffic. The methodology of compulsory periodical inspections was applied during initial tests. Vehicles were examined on typical control stands and in road tests. A special methodology for road tests for coaches with anti-lock systems was elaborated. Additional checks were carried out in cases when the results of basic tests were unsatisfactory. More than 50 vehicles of the total number of examined buses were faulty.
\end{abstract}

Keywords: road transport, road traffic, buses, technical conditions

\section{Introduction}

Buses are considered safer than other motorized modes of transportation. However, there is still considerable number of crashes involving buses every year [1-3]. The majority of research works have concerned road accidents involving buses at low speed. The road incidents have been classified as active ones and passive ones [2], depending on the season of the year, the weather conditions, time of the day, the type of a bus [4], skills, age, experience, sex, cultural background of the drivers [5]. The technical state of a vehicle may be less important in case of crash analysis at low speed, but it is very important at high speed, especially for inter-city buses and coaches.

The analysis of the results of investigations, which were carried out in scope of securing safety in road traffic, allowed to find an assessment of technical stand of buses as a very important problem [6-8]. The safety of duty vehicles in road traffic is very important because of potential hazards of peoples' life and health, damage and loss of freight and high costs of crash effects. The technical state of all vehicles has been examined during required periodical inspections, but in spite of this, the technical conditions of large number vehicles has been poor.

The range of inspections and their frequency have been determined according to the law of each country. The methodology and frequency has been determined in accordance with domestic legislation. The methodology of technical inspections concerns only some important systems of vehicles but not all. For example, anti-lock systems, retarders, adaptive cruise control systems, speed limitation devices etc. have not been examined.

The check methodology of many vehicle systems, which are important for traffic safety in buses, especially coaches, has not been worked out yet.

The examinations of 120 buses in scope of securing safety have been carried out to determine 
the causes of vehicle disabilities, which are important in road traffic. M2 and M3 bus categories including coaches were examined as well.

M2 are vehicles with more than eight passenger seats and a mass not exceeding 5 tones, while M3 exceed the weight of 5 tones. In the carried out analysis, the results of investigation concern M2 buses of a capacity not exceeding 22 passengers class B, which means that vehicles were not designed to carry standing passengers, and M3 buses class II and III (coaches). All M3 buses had a mass exceeding 12 tones.

Specification of vehicle types and examined vehicle age have been presented in Tab. 1.

Tab. 1. Specification of the examined vehicle age

\begin{tabular}{|l|c|c|c|c|c|c|}
\hline \multirow{2}{*}{$\begin{array}{c}\text { Vehicle } \\
\text { category }\end{array}$} & \multicolumn{5}{|c|}{ Percentage of vehicles in age group } & \multirow{2}{*}{$\begin{array}{c}\text { Total number } \\
\text { of vehicles }\end{array}$} \\
\cline { 2 - 6 } & $2-3$ years & $4-5$ years & $6-7$ years & $8-9$ years & $\begin{array}{c}10 \text { years } \\
\text { and more }\end{array}$ & \\
\hline M2/B & & 2 & 3 & 5 & & 10 \\
\hline M3/II & & 8 & 12 & 10 & & 30 \\
\hline M3/III & 5 & 26 & 21 & 19 & 9 & 80 \\
\hline
\end{tabular}

\section{Methods of vehicle examinations}

The methodology, which was applied during examination of buses, was similar to tests, which had been used in previous examinations of passenger cars and duty vehicles [8].

The investigations were carried out in two stages. The initial tests were based on typical periodical inspections. The vehicles were examined in order to define technical states and typical faults, significant for assuring safety in road traffic. The analysis concentrated on the feasibility of detecting faults, which can be determined using conventional diagnosing methods. The way of fixing the fault was also defined. During the examination, organoleptic methods, road and stand tests were applied. The vehicles were examined in order to define technical conditions and typical faults regarding traffic safety. The analyses concentrated on the possibilities of diagnosing any faults, which can be determined using conventional diagnosing methods.

For each category of buses, suitable tests according to binding rules of periodic vehicle inspections were carried out. For faulty vehicles, different diagnostic methods such as diagnosing by on-board diagnostic systems using diagnostic connectors, the measurements of electrical values while testing, additional road tests were conducted.

The examinations of brake systems were carried out in the course of road and stand tests, according to domestic and ECE regulations. The types of tests have been presented in Tab. 2 and algorithm of vehicle examinations has been presented in Fig. 1.

Tab. 2. Tests, which were applied during examinations of vehicles

\begin{tabular}{|c|c|c|c|}
\hline \multirow{2}{*}{ Test / Way of examination } & \multicolumn{3}{|c|}{ Bus category } \\
\cline { 2 - 4 } & $\mathrm{M} 2 / \mathrm{B}$ & $\mathrm{M} 3 / \mathrm{II}$ & $\mathrm{M} / \mathrm{III}$ \\
\hline Braking test on a roller stand & $\mathrm{x}$ & $\mathrm{x}$ & $\mathrm{x}$ \\
\hline Road braking test & $\mathrm{x}$ & $\mathrm{x}$ & $\mathrm{x}$ \\
\hline Examination of steering system & $\mathrm{x}$ & $\mathrm{x}$ & $\mathrm{x}$ \\
\hline Anti-lock system test & & $\mathrm{x}$ & $\mathrm{x}$ \\
\hline On-board diagnostic test & & & $\mathrm{x}$ \\
\hline Detailed diagnostic tests & $\mathrm{x}$ & $\mathrm{x}$ & $\mathrm{x}$ \\
\hline
\end{tabular}




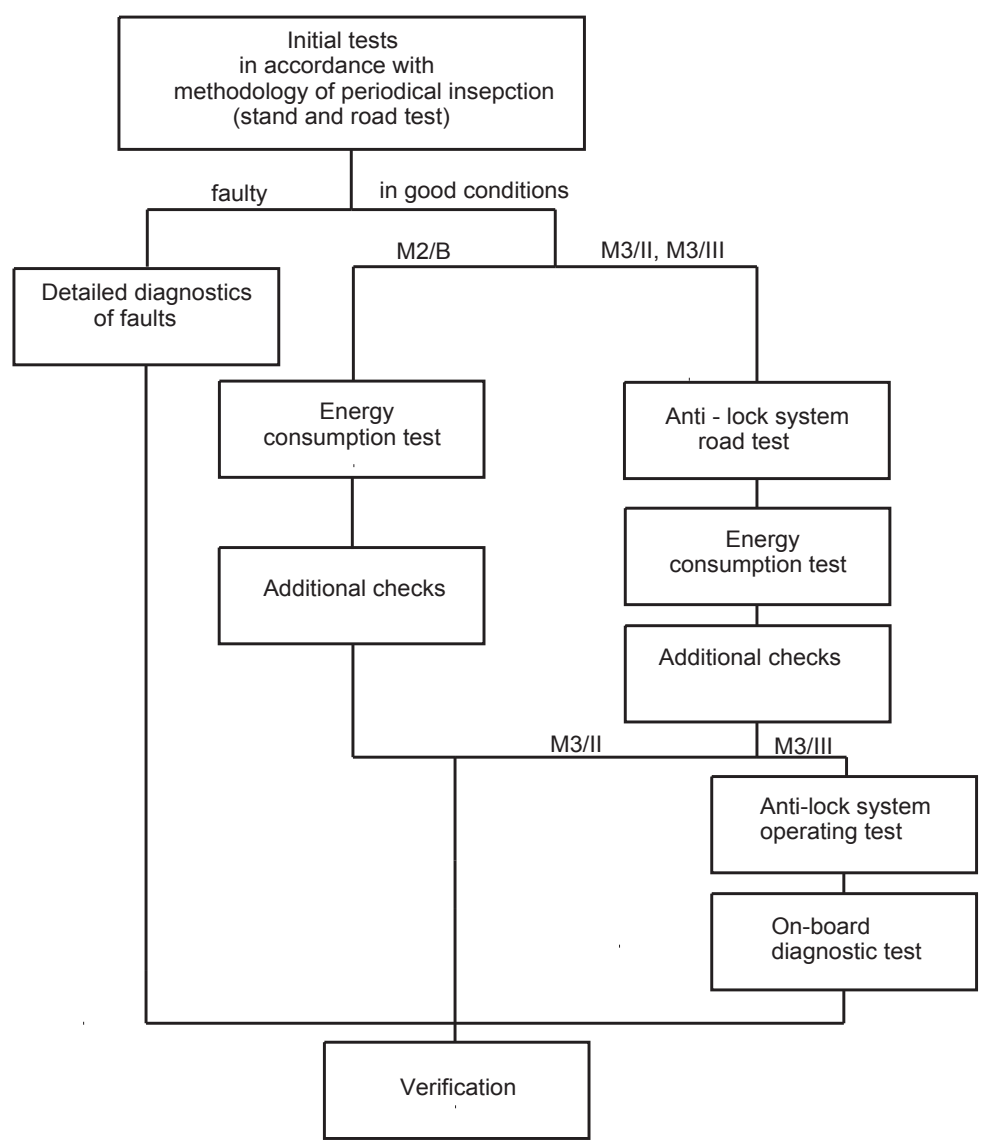

Fig. 1. Algorithm of vehicle examinations

All coaches within M3 category, which were examined, had pneumatic brake systems with anti-lock system category 1, according to ECE Regulation No. 13. Requirements of ECE regulations formed the basis of elaborating new road tests for these vehicles. During the examinations for vehicles with pneumatic anti-lock system, the energy consumption test, and operating test when an axle passes from a high-adhesion surface to a low-adhesion surface were carried out. The initial speed for all the tests was between $50-60 \mathrm{~km} / \mathrm{h}$. Additionally, for all vehicles, when it was possible, on-board diagnostic test was made. Additional detailed diagnostic tests for all faulty vehicles were also performed.

\section{Examination results}

Taking into consideration safety securing aspects for 63 examined buses, the initial test results showed that the technical conditions were poor. The additional diagnostic tests allowed recognizing faulty systems and elements of vehicles, the kinds and causes of damages. However, in many cases faults were not recognized using common diagnostic methods.

The analysis of faults for each category of the examined buses can be classified as faults of systems, which have direct impact on driving safety like, brake system, steering system, suspension system, indicators and lights, chassis system and faults that diminish the comfort of driving and the safety of freight. Examination results for all vehicles have been shown in Fig. 2. The results for each category of buses have been presented in Tab. 3. There have been far more faults of brake system in each category. Forty five per cent out of total number of faults of brake system were connected with anti-lock system. It is probably due to insufficient quality maintenance. 


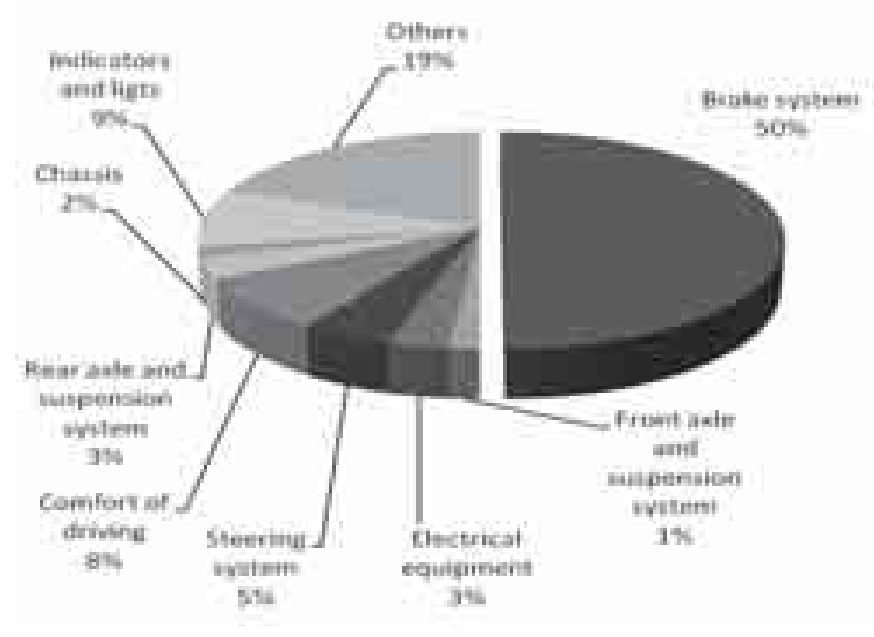

Fig. 2 Structure of vehicle faults

Tab.3. Structure of vehicle faults for particular vehicle categories (number of faults)

\begin{tabular}{|c|c|c|c|c|}
\hline \multirow[t]{2}{*}{ Faulty system } & \multicolumn{3}{|c|}{ Vehicle category } & \multirow{2}{*}{$\begin{array}{l}\text { Total number } \\
\text { of faults }\end{array}$} \\
\hline & $\mathrm{M} 2 / \mathrm{B}$ & M3/II & $\mathrm{M} 3 / \mathrm{III}$ & \\
\hline Brake system & 3 & 12 & 48 & 63 \\
\hline Front axle and suspension system & & 2 & & 2 \\
\hline Electrical equipment & 1 & 3 & & 4 \\
\hline Steering system & & 2 & 4 & 6 \\
\hline Comfort of driving & 1 & 4 & 5 & 10 \\
\hline Rear axle and suspension system & & & 4 & 4 \\
\hline Chassis & & 2 & & 2 \\
\hline Indicators and lights & & 7 & 4 & 11 \\
\hline Others & 2 & 10 & 12 & 24 \\
\hline Total $\mathrm{n}$ & faults & & & 126 \\
\hline
\end{tabular}

Taking into consideration the feasibility of fault diagnosis and the technology of repairs, it is possible to distinguish the following aspects: normal wear during operation, abnormal mechanical faults, faults that are connected with engine control unit and electrical system, dynamic and corrosion fatigue.

The percentage of buses with faults for each examined bus category, including vehicles which technical condition was a threat to traffic safety, has been presented in Fig 3.

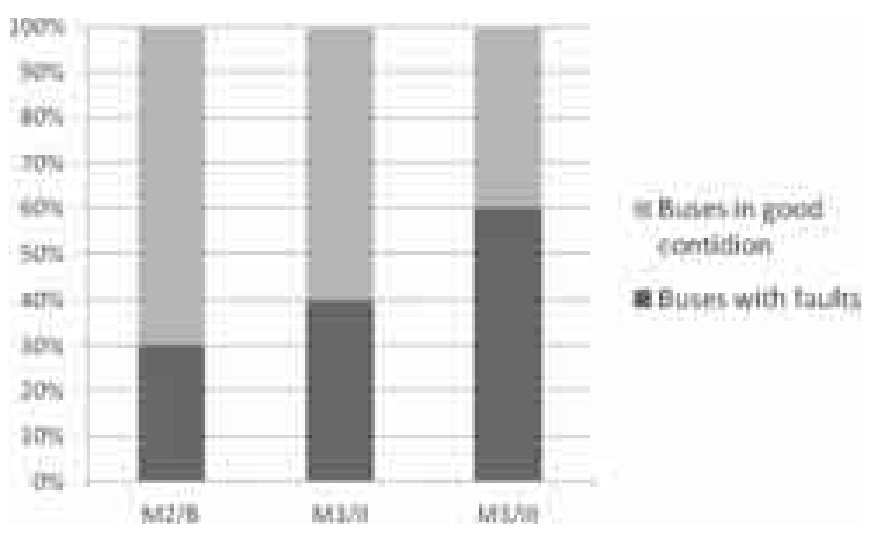

Fig. 3. The percentage of buses with faults in the examined categories 
The majority of buses with pneumatic anti-lock systems were faulty. The damages had big negative effects on air consumption while using brake system on low-adhesion surface. Such cases are particularly dangerous. In many cases, the causes of faults were not recognized because the common brake stand tests were insufficient.

The analysis of detailed diagnostic results and verifications during repairs, allowed identifying faulty parts for each category of the examined buses. The results of verifications have been shown in Fig 4.

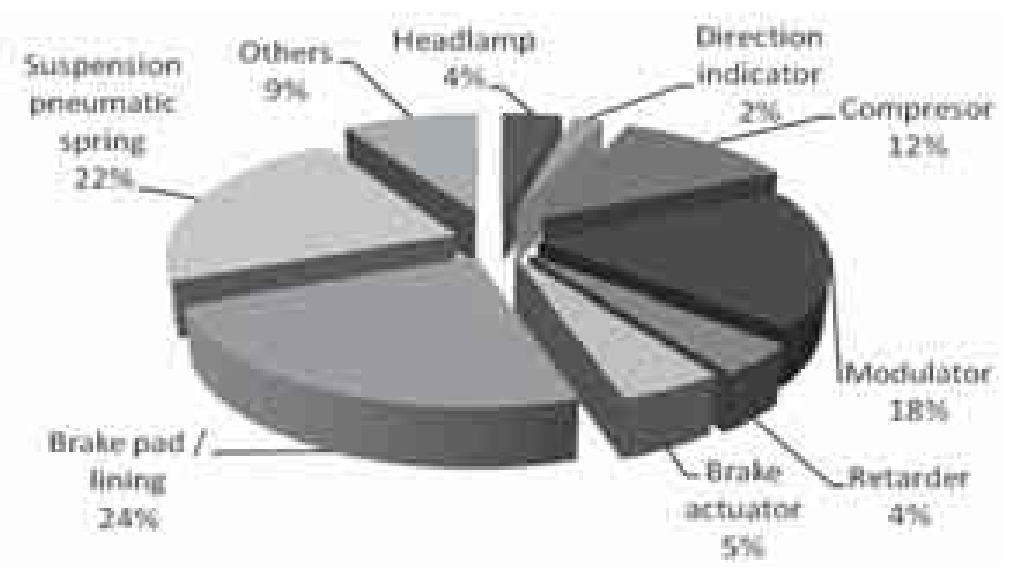

Fig. 4. Structure of faults of particular parts for busesM3/III

For brake pneumatic systems with anti-lock system, apart from normal wear, most faults concern modulators and compressors.

The structure of bus faults was compared to the results of investigations, which had been presented in previous papers [8]. The results of comparison between the fault structure of buses $(\mathrm{M})$ and duty vehicles $(\mathrm{N})$ have been presented in Fig. 5.

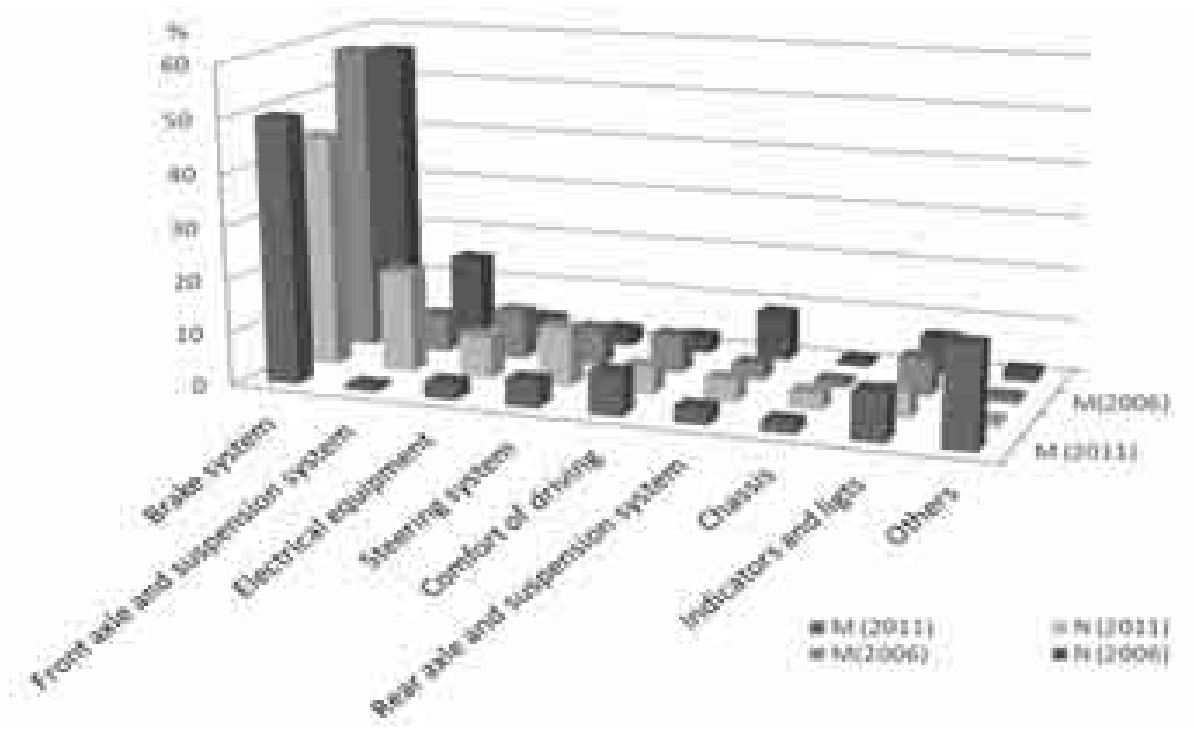

Fig. 5. Structure of vehicle faults - results of investigations which were carried out in 2006 and 2011

The results of investigations showed that describing only the technical conditions of brake systems by calculation of braking rate is unreliable. The calculation results depend on the total mass of vehicle. The examinations of M3 category buses during road tests are difficult because of a large total mass of vehicle, large size, the difference between maximum mass and real mass of a bus and lack of specific test road section for this kind of vehicles. 


\section{Conclusion}

A large number of faulty vehicles was the result of applying more restrictive criteria, which were used in examination tests. The increased number of tests and the kinds of tests, which were applied during the examinations, allowed detecting significantly more types of faults compared to the results of common inspections. Anti-lock road test provided satisfying results of the examinations; however, it is difficult to apply in service stations. The structure of faults, which was revealed during investigations carried out in 2006 and 2011, is almost the same, but the percentage of faulty vehicles with serious damages in 2011 was lower. The reduction of number of faulty vehicles can depend on improving the quality of maintenance and more stringent traffic safety control. Crash statistics are one of the most important data source for road safety policy. However, the collection of traffic accident data could be misleading or incomplete for many reasons. One reason is the fact that the technical conditions of vehicles have been neglected so far.

\section{References}

[1] Chimba, D., Sando, T., Kwigizile, V., Effect of bus size and operations to crash occurrences, Accident Analysis and Prevention 42, pp. 2063-2067, 2010.

[2] Wahlberg, A. E., Characteristics of low speed accidents with buses in public transport. Accident Analysis and Prevention 34, pp. 637-647, 2002.

[3] Albertsoon, P., Falkmer, T., Is there a pattern in European bus and coach incidents? A literature analysis with special focus on injury causation and injury mechanisms, Accident Analysis and Prevention 37, pp. 225-233, 2005.

[4] Yang, J., Peek-Asa, C., Heiden, E., Falb, S., Ramirez, M., Incidence and characteristics of school bus crashes and injuries. Accident Analysis and Prevention 41, pp. 336-341, 2009.

[5] Strathman, J., Wachana, P., Callas, S., Analysis of bus collision and non-collision incidents using transit ITS and other archived operations data. Journal of Safety Research 41, pp. 137-144, 2010.

[6] Filipczyk, J., The inspection of cars in the scope of traffic safety and environmental protection - the present situation and the prospects of development, Transport Problems 2009, I International Scientific Conference, pp. 118-125, Katowice - Kroczyce 2009.

[7] Filipczyk, J., Methods of assessing the technical state of vehicles for securing safety in road traffic, Transactions on Transport Systems Telematics \&Safety, pp. 156-163, Gliwice 2009.

[8] Filipczyk, J., Faults of duty vehicles in the aspects of securing safety, Transport Problems, Vol. 6, Is. 1, pp. 105-110, 2011. 